\title{
MATHBA'AH ISLAMIAH DI MINANGKABAU: SEJARAH SEBUAH PENERbit ISLAM MELINTASI TIGA ZAMAN (1924-1972)
}

\author{
Halimatus Sakdiah ${ }^{1}$
}

${ }^{1}$ Institut Agama Islam Negeri (LAIN) Bukitinggi, Indonesia, e-mail: balimatussakdiab421997@gmail.com$$
\text { (c) (1) (2) }
$$

(C)2020 by the authors. Submitted for possible open access publication under the terms and conditions of the Creative Commons Attribution (CC-BY-SA) license (https://creativecommons.org/licenses/by-sa/4.0/) DOI : http://dx.doi.org/10.30983/it.v4i2.3442

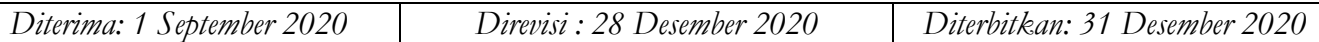

Abstract

This article wants to know the history and development of the Mathba'ah Islamiah publisher from its early days until it disappeared from the circulation of its publishing and printing world. In the 20th century, there were many publishers and printers in Bukittinggi. This arose in response to requests for reading material from educated people connected with schools' growing bloom in several places in West Sumatra. Publishing and printing work was carried out by colonial circles and Western intellectuals and involved natives from within the Muslim faith. The research method used is the historical research method. From the research results, it was found that the publishing of Mathba' ah Islamiah was a publication founded by H.M.S Sulaiman on the advice of the elderly scholars, Syekh Sulaiman Arrasuli, Syekh Mubammad Jamil Jaho and Syekh Abbas Qadhi Lading Laweh. This publication published the works of Minangkabau clerics and books used in the Madrasas of the Old People at that time. Not only publishing books, but the Mathba'ab Islamiah publisher also printed the Koran and its translations sent to various regions in Sumatra and even reached several parts of the archipelago.
\end{abstract}

Keywords: Matbba'ab Islamiab; HMS Sulaiman; Publishing; Minangkaban

\begin{abstract}
Abstrak
Artikel ini hendak mengetahui sejarah dan perkembangan penerbit Mathba'ah Islamiah sejak masa awal hingga hilang dari peredaran dunia penerbitan dan percetakan Tanah Air. Pada abad ke-20 terdapat banyak penerbit dan percetakan di Bukittinggi. Hal ini timbul sebagai tanggapan atas permintaan bahan bacaan dari orang terdidik dalam hubungannya dengan tumbuh mekarnya sekolah-sekolah di sejumlah tempat di Sumatera Barat. Kerja penerbitan dan percetakan tidak saja dilakukan oleh kalangan kolonial dan kaum terdirik Barat, tetapi juga melibatkan kaum pribumi dari kalangan agama Islam. Metode penelitian yang digunakan ialah metode penelitian sejarah. Dari hasil penelitian ditemukan bahwa penerbitan Mathba'ah Islamiah adalah penerbitan yang didirikan oleh H.M.S Sulaiman atas anjuran dari ulama kaum tua Syekh Sulaiman Arrasuli, Syekh Muhammad Jamil Jaho dan Syekh Abbas Qadhi Lading Laweh. Penerbitan ini menerbitkan karya-karya ulama Minangkabau dan juga kitab-kitab yang dipakai di madrasah-madrasah Kaum Tua ketika itu. Tak hanya menerbitkan buku-buku saja penerbit Mathba'ah Islamiah ini juga mencetak Al-Quran dan terjemahannya yang dikirim ke berbagai daerah di Sumatra bahkan menjangkau beberapa daerah Nusantara.
\end{abstract}

Kata Kunci: Mathba'ah Islamiah; HMS Sulaiman; Penerbitan; Minangkabau

\section{Latar Belakang}

Sumatera Barat sebagaimana yang diketahui sekarang adalah salah satu wilayah geopolitik Indonesia yang secara historis sebenarnya merupakan wilayah kultural Minangkabau. Pada tahun 1837 daerah ini dikuasai oleh pemerintah kolonial Belanda, dan menjadi wilayah administrasi politik

Government Sumatera's westkust yang dikepalai oleh seorang Residen. ${ }^{1}$ Pada masa penjajahan Jepang wilayah ini disebut dengan Sumatra Nishi Kaigun Shu. Setelah merdeka wilayah ini menjadi Provinsi Sumatera Tengah dengan ibukota Bukittinggi dan kemudian pada tahun 1957 menjadi provinsi Sumatera Barat.

1 Hendra Naldi, Booming Surat Kabar di Sumatra's Westkust (Yogyakarta: Ombak, 2008), 12. 
Penduduk Sumatera Barat umumnya adalah etnis Minangkabau yang mayoritas beragama Islam dengan sejarah keagamaan yang kompleks. ${ }^{2}$ Pada abad 20, di antaranya, terjadi polemik keagamaan dari kalangan kaum tua maupun kalangan kaum muda. Polemik tersebut memberi pengaruh terhadap arah intelektual ulama. Dalam proses polemik itu, kebutuhan literasi menjadi perhatian ulama. ${ }^{3}$ Sehingga pada awal abad ke-20 di Minangkabau banyak bermunculan percetakan. Percetakan tersebut didominasi oleh buku-buku beraksara Arab dan Arab-Melayu. Hal ini dikarenakan tingginya minat baca seiring lahirnya tulisantulisan ulama di kawasan ini. Oleh karena itu tidak heran bila Minangkabau pada masa itu menjadi pusat intelektual Islam ditandai dengan berdirinya ratusan madrasah hasil formulasi dari berdirinya surau-surau yang ada di abad sebelumnya. $^{4}$

Keterlibatan perusahan pribumi di bidang percetakan dan penerbitan di Minangkabau dimulai pada abad 20. Ditandai dengan bermunculannya surat kabar milik orang Minangkabau yang pertama yaitu Alam Minangkabau tahun 1904. Pemiliknya adalah dua orang haji yakni Haji Mohd Salleh dan Haji Mohd Amin. Upaya kedua tokoh tersebut kemudian diteruskan oleh Mahyoedin Datoek Soetan Maharadja yang pada tahun 1911 sang Datuk mendirikan percetakan dan penerbitan Perserikatan Orang Alam Minagkabau (OAM).

Selanjutnya berturut-turut lahir penguasa pribumi di Minangkabau di bidang percetakan. ${ }^{5}$

${ }^{2}$ Irhash A. Samad dan Danil M. Chaniago, Islam dan Praktis Kultural Masyarakat Minangkabau (Jakarta: PT Tintamas Indonesia, 2007),17.

${ }^{3}$ Apria Putra, "Ulama dan Karya Tulis: Diskursus Keislaman di Minangkabau Awal Abad 20," Fuaduna: Jurnal Kajian Keagamaan dan Kemasyarakatan 1, no. 2 (2017): 134-47.

4 Apria Putra, "Drukkerij Al-Islamiah Fort de Kock: Penerbit Turats Ulama Minangkabau di Masa Pemerintah Belanda," Tarbiyah Islamiah 2, no.1 (2014): 12, https:/ / tarbiyahislamiyah.id/drukkerij-al-islamiyah-fortde-kock-penerbit-turats-ulama-minangkabau-di-masapemerintahan-belanda/.
Terdapat puluhan penerbit dan percetakan pada saat itu, antara lain yang terkenal Samaratul Ikhwan (Bukittinggi), Kahamy (Bukittinggi), Limbago (Payakumbuh), Percetakan Alam Minangkabau (Payakumbuh), Tandikat (Padang Panjang), Sa'diyah (Padang Panjang), Al-Moenir (Padang), De Voltherding (Padang), Percetakan Orang Alam Minangkabau Datuk Sutan Maharaja (Padang), Plubomer (Padang), Mathba'ah Al Islamiyah (Bukittinggi), ${ }^{6}$ Tja Endar Bungsu, Drukkerij Sumatera, Oost Indisch Boekhandel dan Drukkerij T. Pen, Bemidelling Bureau, Persatuan Muslim Indonesia dan Gazaira (Padang), Minangkabau (Pariaman), Pemuda Muhammadiyah (Kurai Taji), Oesaha Djasa (Sulit Air), Soera Kaum Ibu (Padang Panjang), Serikat Keluarga (Koto Gadang), N.V. Nusantara dan Pustaka Ilmu (Fort De Kock). ${ }^{7}$

Dari sederetan nama penerbitan dan percetakan yang ada tertulis dalam catatan kolonial awal abad 20 tersebut adalah Mathba'ah Islamiyah yang merupakan penerbitan dan percetakan yang menarik untuk ditinjau lebih jauh. Hal ini disebabkan karena, pertama Mathba'ah Islamiah didirikan oleh H.M.S Sulaiman yang mempunyai reputasi dikalangan ulama Minangkabau H.M.S Sulaiman juga termasuk salah satu dari sederetan tokoh yang membidani lahirnya Persatuan Tarbiyah Islamiah. ${ }^{8}$ Kedua, Mathba'ah Islamiah konsen dengan penerbitan ulama Minangkabau, serta kitab-kitab untuk madrasah dan surau. Ketiga percetakan ini

5 Sastri Sunarti, "Suara-Suara Islam Dalam Surat Kabar Dan Majalah Terbitan Awal Abad 20 di Minangkabau," Turas: Jurnal XXI, no. 2 (2015): 231.

6 Putra, "Drukkerij Al-Islamiah Fort de Kock: Penerbit Turats Ulama Minangkabau di Masa Pemerintah Belanda," 12.

7 Sunarti, "Suara-Suara Islam dalam Surat Kabar dan Majalah Terbitan Awal Abad 20 di Minangkabau," 231.

8 Apria Putra, "Drukkerij Al-Islamiah Fort de Kock: Penerbit Turats Ulama Minangkabau di Masa Pemerintah Belanda,"12. 
tercatat sebagai salah satu percetakan Al-Qur'an pertama di Indonesia baik yang terjemahan maupun yang biasa, bahkan klise dari Al-Quran tersebut masih disimpan sampai sekarang. ${ }^{9}$ Keempat, penerbit ini berjasa menerbitkan karya langka secara cuma-cuma dan dibagibagikan demi kemaslahatan kaum muslim ketika itu. Hal ini dituliskan oleh Syekh Haji Yunus Yahya Magek yang pernah mencetak buku karangan ayahnya di Mathba'ah Islamiah. H.M.S. Sulaiman mencetaknya dengan jumlah yang sangat banyak. Sebagian diberikan kepada Syekh Haji Yunus Yahya Magek sebagai hadiah dan sebagian lagi barulah beliau jual. ${ }^{10}$

Drukkerij Al-Islamiah menjadi salah satu dari sederatan toko buku di Sumatera Tengah ketika itu yang melengkapi keperluan kitabkitab agama yang dipelajari di madrasah (pesantren). Salah satunya Madrasah Tarbiyah Canduang yang ketika itu dipimpin oleh Syekh Sulaiman Arasuli. Berdasarkan hasil wawancara yang penulis lakukan dengan Syek Zamzami Yunus yang tidak lain adalah salah satu murid yang belajar di Madrasah Tarbiyah Islamiah Canduang. Semasa beliau belajar di sana, beliau sering melihat H.M.S Sulaiman datang ke sekolah dan bertemu dengan Syekh Sulaiman Arrasuli. Bahkan buku-buku yang dipakai belajar ketika itu merupakan buku terbitan dari Mathba'ah Islamiah. ${ }^{11}$

Selain mencetak sendiri, HMS Sulaiman juga mendatangkan kitab-kitab terbitan dari Mesir. Kemudian menjadikan tokonya untuk mendistribusikan kepada sekolah-sekolah agama yang membutuhkan. Untuk itu HMS Sulaiman juga melengkapi Mathba'ah Islamiah dengan sebuah mesin cetak aksara Arab.

Haji Sulaiman wafat di Padang karena menderita sakit. Setelah wafatnya Haji Sulaiman, kabar mengenai Drukkerij Islamiah

${ }^{9}$ Dedi Arsa, "Pembentukan Masyarakat Literal di Sumatra Barat: Perkembangan Awal Perpustakaan dan Toko Buku," Khazanah 9, no. 1 (2019): 31-40.

10 Yunus Yahya, Riwayat Ulama Syafia'i (Magek: Persatuan Murid-Murid Tarbiyah Islamiah, 1976), 34. yang terkenal itu tidak terdengar lagi. Bahkan rekaman tentang penerbit ini tidak banyak ditemukan sampai saat ini, seperti buku-buku yang pernah diterbitkan, Matba'ah Islamiah hanya dikenal dari catatan-catatan sepenggal. Penulis berharap setelah dilakukan penelitian ini bisa menjadi motivasi untuk memunculkan kembali penerbit di Sumatera Barat kususnya Bukittinggi yang menerbitkan kembali turats ulama Minangkabau

Penelitian ini menekankan kepada bagaimana proses kelahiran dan perkembangan Mathba'ah Islamiah, buku-buku apa saja yang diterbitkan oleh Mathba'ah Islamiah, sistem managerial penerbit Mathba'ah Islamiah ini dalam hal permodalan dan pekerja, penjualan dan promosi, serta hubungan dengan perkembangan kehidupan keagamaan khususnya dari kalangan tradisional, dan alasan berhentinya penerbitan Mathba'ah Islamiah di kemudian hari.

Setelah dilakukan tinjau keperpustakaan sedikit sekali ditemukan pembahasan yang telah pembahas tentang penerbitan maupun tokoh HMS Sulaiman, sepanjang pengetahuan penulis buku yang relavan dengan penelitian penulis antara lain artikel Dedi Arsa yang menginformasikan pembentukan masyarakat literal lewat keberadaan perpustakaan dan toko buku di Sumatra Barat. Dalam artikel ini Dedi Arsa juga menyinggung tentang penerbitan Mathba'ah Islamiah; dituliskan bahwa Mathba'ah Islamiah merupakan penerbitan yang menerbitkan Al-Quran pertama di Nusantara dan juga menjual karya ulama Timur Tengah. Hanya saja dalam artikel ini tidak disinggung tentang bagaimana sejarah dan perkembangan penerbitan ini dalam periodenya yang panjang itu dengan lebih detail. ${ }^{12}$ Begitu juga dengan Apria Putra yang

\footnotetext{
${ }^{11}$ Syekh Zamzami Yunus (Murid Syekh Sulaiman Arrasuli) Wawancara, 18 Januari 2020.

12 Arsa, "Pembentukan Masyarakat Literal di Sumatra Barat: Perkembangan Awal Perpustakaan dan Toko Buku," 31-40.
} 
menulis tentang riwayat singkat toko buku dan penerbit Drukkerij Al-Islamiah Fort De Kock atau Mathba'ah Islamiah yang terkenal menjual dan mencetak buku-buku agama Islam. ${ }^{13}$ Kedua artikel ini merupakan gambaran umum dan belum banyak menyentuh bagaimana toko buku berperan dalam pembentukan golongan terdidik dalam masyarakat Minangkabau.

Beberapa karya lain yang juga membahas penerbit ini masih secara ringkas dan singkat di antaranya sebuah buku karangan Alaidin Koto $^{14}$ yang membahas tentang Persatuan Tarbiyah Islamiah, kelahiran, perkembanganya, serta paham dari Persatuan Tarbiyah Islamiah; buku karangan Zikri Fadila $^{15}$ yang memfokuskan tinjauan kepada dunia penerbitan di Fort de kock pada tahun 1901-1942. Zikri fadila membahas dengan sangat baik mengenai penerbitan yang ada di Bukittinggi pada masa kolonial, namun hanya membahas sedikit tentang Mathba'ah Islamiah secara ringkas, seperti beberapa buku yang pernah diterbitkan oleh Mathba'ah Islamiah, tetapi Zikri tidak menulis bagaimana sejarah perkembangan toko buku dan penerbitan ini kemudian. Buku karangan Dedi Arsa ${ }^{16}$ hanya membahas sepintas tentang penerbitan Islamiah dan hanya sebagai pelengkap tulisannya, itupun sudah ada juga dicantumkan sebagian besarnya dalam artikelnya di jurnal sebelumnya yang sudah ditinjau.

Penelitian ini adalah penelitian sejarah deskriptif-naratif dan menggunakan metode penelitian sejarah modern. Metode penelitian sejarah terdiri dari beberapa tahapan berikut ini: Heuristik, berupa kegiatan penjajakan, pencarian, dan pengumpulan sumbersumber ${ }^{17}$ yang akan diteliti terkait topik yang akan di bahas, baik yang terdapat dilokasi

13 Putra, "Drukkerij Al-Islamiah Fort de Kock: Penerbit Turats Ulama Minangkabau di Masa Pemerintah Belanda,"12.

14 Alaidin Koto, Pemikiran Politik Persatuan Tarbiyah Islamiah 1945-1970 (Riau: UIN Suska Press, 1996), 56.

15 Zikri Fadila, Penerbitan Minangkabau Masa Kolonial (Yogyakarta: Gre Publising, 2018), 43. penelitiaan, temuan benda maupun sumber lisan. ${ }^{18}$ Pada tahap awal pengumpulan sumber, untuk mendapatkan data-data yang berkaitan dengan penelitian ini penulis mengadakan penelitian kepustakaan. Sesuai dengan tujuan penelitian ini, maka yang menjadi sumber primer adalah buku hasil terbitan dari Mathba'ah Islamiah, suratkabar Warta Perniagaan yang memuat iklan tentang penerbitan Mathba'ah Islamiah yang diterbitkan pada tahun 1927. Majalah Soerti yang terbit juga pada masa itu, majalah yang diprakasai oleh kaum Perti, dalam majalah tersebut memuat iklan dan buku yang dicetak oleh Mathba'ah Islamiah pada masa itu, buku karangan Syekh Yunus Yahya magek ditulis pada tahun 1946 yang di dalamnya memuat biografi singakat HMS Sulaiman. Sedangkan sumber sekunder adalah wawancara dengan cucu kandung H.M.S Sulaiman yaitu Haji Datuak Panindiah berusia 83 tahun dan tokoh masyarakat yang mengenali beliu ketika masih hidup yaitu Zamzami Yunus berusia 73 tahun. Selain wawancara dilengkapi juga dengan buku yang berhubungan dengan penerbitan, jurnal, diantaranya jurnal karangan dari Apria Putra dan Dedi Arsa yang juga membahas tentang penerbit dan toko buku milik H.M.S. Sulaiman ini.

Untuk menyelidiki apakah sumbersumber sejarah itu asli maupun penjelasan yang juga melacak data-data itu memiliki kredibilitas kemudian mengadakan pengujian dan penelitian terhadap sumber yang ditemukan dalam kritik eksternal dan internal. Kritik eksternal dilakukan untuk mengetahui autensitas atau keaslian sumber. Kritik eksternal adalah cara melakukan verifikasi atau pengujian terhdap aspek-aspek luar sumber

16 Dedi Arsa, Celana Pendek dan Cerita Pendek (Yogyakarta: Basabasi, 2008), 12.

17 Dudung Abdurrahaman, Metodologi Penelitian Sejarah Islam (Yogyakarta: Ombak, 2012), 3.

18 Sulasman, Metodologi Penelitian Sejarah (Bandung: Pustaka Setia, 2014), 93. 
sejarah. ${ }^{19}$ Pengujian kelayakan sumber-sumber sejarah yang akan dijadikan bahan utama dan penunjang dalam penelitian sejarah. Jadi kritik ini lebih bersifat fisik dan bukan isi dari sumber-sumber tersebut kritik eksternal yang telah dilakukan adalah terhadap sumbersumber literatur yang ada di dalam berbagai tempat. Dalam tahapan kritik ekternal, buku hasil terbitan, majalah Soerti, buku karangan Syekh Yunus Yahya Magek, surat kabar Warta Perniagaan merupakan sumber primer yang digunakan dalam penulisan skripsi ini karena surat kabar, majalah dan buku-buku tersebut sezaman dengan penelitian yang sedang dilakukan. Sehingga surat kabar, majalah, buku-buku tersebut dapat dipertanggung jawabkan keasliannya. Sementara kritik internal menekankan pada keotentikan (nilai kebenaran) pada isi untuk mendapatkan kevalidan data yang di kandungnya. Krtik internal ini mulai bekerja setelah kritik eksternal selesai, menentukan bahwa dokumen yang diperoleh adalah dokumen yang di perlukan. Dengan kata lain pengujian terhadap kesahihan isi atau informasi dari sebuah sumber. tujuanya agar penulis tidak begitu saja menerima sumber-sumber yang didapatkan. Kritik yang dilakukan pada surat kabar warta perniagaan yang berisikan iklan tentang penerbitan dan percetakan Al-Islamiah dan promosi buku hasil cetakan tersebut. Sedangkan majalah Soerti dan buku karangan Syekh Haji Yunus Yahya Magek berisikan tentang ketokohan H.M.S. Sulaiman.

Setelah melakukan kritik internal maka pada tahap ini dilakukan sintesis dengan menggunakan teknik interpretasi yaitu penafsiran fakta-fakta sejarah. Baik dari sumber tertulis maupun sumber lisan maupun sumber benda. Sehingga terbentuklah kalimatkalimatyang jelas dan logis. Pada tahap ini penulis berusaha menguraikan fakta-fakta sejarah yang didapatkan. Dalam hal ini penulis berusaha semaksimal mungkin menyusun, merangkai dan mencurahkan segenap kemampuan untuk mencari sesuatu yang dimaksud, menyusun rangkuman sejarah kemudian menjelaskan dengan ungkapan historis yang rasional. Tahap ini menjadi sebuah puncak dari metode penelitian sejarah. Di sini orang sejarawan dituntut mengarang menggunakan bahasa yang sederhana dengan tetap menggunakan kaidah-kaidah keilmuan.

\section{Latar Belakang Kemunculan Mathba'ah Islamiah}

Pada akhir abad ke-19 dan awal abad ke-20, proses modernisasi di Minangkabay terus berlangsung. Berbagai pembaharuan terus berlangsung dalam kehidupan masyarakat, termasuk di kota utamanya di Fort de Kock (Bukittinggi). Pengaruh Modernisasi Barat dalam berbagai ruang lingkup masyarakat, terutama dalam bidang ekonomi dan pendidikan sangat dirasakan oleh masyarakat. Pembaharuan ekonomi yang dilakukan oleh pemerintah Hindia Belanda adalah dengan menata pengelolaan pasar, dan pengembangan profesi dalam berbagai bidang termasuk penerbit dan hadirnya mesin cetak yang nantinya akan berpengaruh besar terhadap dunia penerbitan buku. ${ }^{20}$

Di sisi lain proses modernisasi di dunia Islam juga terus terjadi. Berbagai pembaharuan terus terjadi terutama pada bidang pendidikan. Para ulama yang telah menempuh pendidikan ke Timur Tengah kemudian memeprakasai dibentuknya pesantren-pesantren dan madrasah sebagai lembaga pendidikan Islam. Berkembangnya pendidikan lambat laun akan menghasilkan kaum intelektual yang pandai baca tulis dan membutuhkan bahan bacaan serta sarana menuangkan ide-ide, pemikiran dan gagasan mereka secara tertulis Kepandaian tulis baca kemudian menghasilkan kemudian menghasilkan buku-buku yang bermamfaat 
bagi masyarakat. Kebutuhan ini kemudian didukung oleh perkembangan ekonomi dunia percetakan dan penerbitan.

Perkembangan dunia pendidikan Islam di Sumatera's Westkust pada masa awal kemudian melahirkan beberapa penerbit pribumi swasta yang mempunyai tujuan untuk mengembangkan agama Islam. Salah satu penerbit yang aktif menerbitkan buku-buku yang berkaitan dengan agama Islam adalah penerbitan Mathba'ah Islamiah.

Drukkerij Islamiah atau Mathba'ah Islamiah didirikan oleh Haji Sulaiman atas anjuran dari syekh Sulaiman Arrasuli Canduang, Syekh Mhd. Jamil Jaho Padang Panjang, Syekh Abbas Al-Qhadi Ladang laweh, pada akhir abad 19. ${ }^{21}$ Ketiga ulama yang menganjurkan ini merupakan Ulama Tua Persatuan Tarbiyah Islamiah. Pada masa itu penerbitan Mathba'ah Islamiah terletak di jalan menuju pasa lereng sebelah kanan atau disebut saja jalan syekh Batam yang sekarang toko buku merapi. Toko yang berdiri dua tingkat itu tidak hanya digunakan sebagai percetakan buku tetapi juga sebagai tempat tinggal oleh H.M.S Sulaiman.

Pada awalnya Mathba'ah Islamiah merupakan toko buku yang menjual buku-buku terbitan Timur Tengah maupun ulama Minangkabau. ${ }^{22}$ Kedekatan H.M.S. Sulaiman dengan ulama-ulama Minangkabu memberi peluang baginya utuk menerbitkan naskahnaskah kitab dan buku-buku ulama Minangkabau sendiri.

Kabar tentang perusahaan penerbitan dan percetakan Mathba'ah Islamiah dapat diketahui melalui iklan-iklan, surat kabar dan majalah. Mathba'ah Islamiah termasuk perusahaan percetakan terbesar dan tertua dalam sejarah percetakan Bukittinggi. Percetakan ini menerima cetakan dan menerbitkan buku dalam jumlah besar dan kecil. Buku-buku yang

21 Yahya, Riwayat Ulama Syafia’, 34.

22 Arsa, Celana Pendek dan Cerita Pendek, 70 . di terbitkan kebanyakan adalah buku-buku agama yang berkaitan dengan agama Islam yang ditulis ulama terkemuka di Sumatera Weskust pada masanya.

Meskipun HMS Sulaiman berasal dari golongan kaum tua akan tetapi buku-buku yang diterbitkan tidak hanya dari kalangan kaum tua saja tetapi juga dari kalangan kaum muda, hal ini dibuktikan dengan beliau mencetak buku karangan Syekh Abdul Karim Amrulah atau yang dikenal inyiak Rasul dari kalangan kaum muda.

Selain buku agama penerbitan Mathba'ah Islamiah juga menerbitkan buku tentang adat dan pengetahuan umum seperti ilmu faraid ilmu hadist, ilmu tafsir, ilmu urud dan banyak lainya. Karya-karya yang di terbitkan tersebut kebanyakan digunakan untuk membantu pembelajaran di sekolah-sekolah Madrasah Islmiah, buku-buku agama yang diterbitkan dicetak dalam bahasa Arab, Melayu, atau Arab Melayu. Denga penggunanan mesin cetak beraksara Latin dan Arab. Mesin cetak yang dipesan kusus dari Jerman. Drukkerij AlIslamiah menjadi salah satu dari sekian penerbit terkenal dan mampu melewati tiga zaman: Belanda, Jepang, dan zaman kemerdekaan. ${ }^{23}$

Pada zaman Belanda pemerintah kolonial tidak pernah mengeluarkan undang-undang kusus untuk melarang mengeluarkan peredaran bacaan liar, tetapi mereka berusaha mengambat kelanjutanya dengan menguasai percetakan, penerbit dan peredaran bahan bacaan melalui balai pustaka. Pemerintah melakukan pelarangan ketika terjadi aksi perlawanan atau buku-buku yang diterbitkan berisikan ujaran kebencian terhadap pemerintah Belanda. Hal tersebut berlaku untuk semua percetakan yang ada termasuk Mathba'ah Islamiah, pada zaman kolonial Belanda accounting di penerbitan ini dipegang oleh orang Belanda lansung. Adanya

23 Putra, "Drukkerij Al-Islamiah Fort de Kock: Penerbit Turats Ulama Minangkabau di Masa Pemerintah Belanda," 12. 
orang Belanda dalam perusahan penerbitan Islamiah ini juga menguntungkan bagi penerbit salah satunya mempermudah memesan alat-alat percetakan dari luar negri.

Peralihan masa Kolonial Belanda dengan masa pendudukan Jepang merupakan lembaran sejarah kelam bagi bangsa Indonesia penderitaan yang dialamai bangsa Indonesia terus berlanjut walaupun terdapat perbedaan corak perlakuan antara Belanda dan Jepang tetapi keduanya meninggalkan kesengsaraan dan penderitaan bagi bangsa Indonesia. ${ }^{24}$

Dunia penerbitan dan percetakan yang berkembang di Minangkabau meredup ketika Jepang mulai masuk ke Indonesia yaitu tahun 1942 Terutama di Sumatera Barat. Pada masa keduduka jepang dunia penerbitan mengalami perubahan yang dratis sedikit sekali penerbitan dan percetakan yang mampu bertahan. ${ }^{25}$ Pada penjajahan Jepang penerbitan terus berlanjut hanya saja penerbitan buku dan seluruh jenis media yang ada digunakan oleh para tentara Jepang untuk kepentingan propaganda. Hingga pada akirnya Indonesia merdeka tahun 1945.

Tidak hanya menguasai penerbitan kolonial Jepang juga mulai menutup sekolahsekolah Agama, hal ini sangat berdampak bagi penerbitan buku-buku agama. Termasuk Mathba'ah Islamiah yang pada waktu itu menerbitkan buku-buku pelajaran untuk sekolah agama. sehingga untuk pengiriman buku geraknya menjadi terbatas.

Setelah Indonesia merdeka tahun 1945 balai pustaka menerbitkan buku nasional dan mencetak ulang buku tersebut. Pada masa ini kmbalilah bermunculan penerbit-penerbit suasta lainya. dengan bermotifkan politik. Sedangkan Mathba'ah Islamiah tetap jalan dengan menerbitkan buku-buku pendidikan sekolah agama. Hal ini disebabkan Karena

${ }^{24}$ Muhammad Rijal Fadli, Sistem Ketatanegaraan pada Masa Pendudukan Jepang, (Jakarta: PT Prima, 2019), 190. pemikiran haji Sulaiman yang selalu memikirkan pendidikan bangsa.

Kemudian masuk kepada masa Orde Baru, keadaan penerbitan mengalami perubahan kembali. Yang berbeda pada masa ini adalah penerbitan harus melalui proses sensor dan persetujuan Jaksa Agung. Pada masa-masa ini tak ada permasalahan yang berarti yang di hadapi oleh penerbitan Mathba'ah Islamiah karena buku yang di terbitkan adalah bukubuku agama sehingga tidak ada larangan dari pemerintah.

Setelah kemerdekaan tidak ada masalah yang berarti yang dihadapi oleh penerbitan Mathba'ah Islamiah ini selain karena buku yang diterbitkan tidak bergendre politik pemerintah lebih memperhatikan peraturan politik. Apalagi, pada tahun 1970an kesehatan HMS. Sulaiman mulai menurun, berdasarkan keterangan dari cucunya, Haji Datuak Manindiah, beliau mengidap penyakit struk. Sehingga percetakan mulai dikelolah oleh anak beliau Haji Muchtar degan cucu beliau Datuak Manindiah yang sekarang memiliki toko buku bernama toko buku irama, karena kesehatan yang semakin memburuk beliau pindah kekota Padang dan tinggal bersama anak beliau yaitu Prof, dr. Mahyudin dan istrinya Sariman. Hingga pada tahun 1972 beliau menghembuskan nafas terakirnya di kota Padang.

Setelah beliau wafat percetakan tetap berlanjut tetapi tidak begitu lama. Haji Datuak Manindiah mengatakan penerbitan ini berakir karena kalah saing dengan penerbitan moderen yang semakin banyak bermunculan, baik dari segi hasil yang diterbitkan maupun harga pembuatan buku. Setelah saya tanyakan kenapa tidak dilanjutkan saja dengan membeli mesin yang lebih modren, beliau menjawab pemesanan barang yang semakin sulit, serta

25 Sastri Sunarti, Kelisanan dan Keberaksaraan dalam Surat Kabar Terbitan Awal Minangkabu1859-1940 (Jakarta: Gramedia, 2013), 107. 
untuk mendatangkan kertas cetak itu juga membutuhkan modal yang besar karena di Bukittinggi tidak menjual kertas untuk percetakan. Sehingga dibuat keputusan untuk memesan buku dari penerbit lain, sedangkan mesinnya dijual dan sekarang tidak diketahui keberadaan mesin tersebut.

\section{Biografi Pendiri}

Haji Sulaiman atau sering juga di sebut H.M.S.Sulaiman merupakan salah satu tokoh penting yang dimiliki oleh Minangkabau. Selain keilmuanya beliau juga berkontribusi dalam berbagai hal untuk memajukan Minangkabau. Salah satunya adalah dengan mendirikan toko buku dan percetakan yang telah menerbitkan karya-karya ulama Minangkabau dan sebagian disumbangkan untuk sekolah-sekolah. salah satu karya cetak beliau yang sangat terkenal adalah Al-Quran.

Haji Sulaiman sendiri dilahirkan di Kampuang Galuang Kenagarian Sungai Puar pada tahun $1880 .{ }^{26}$ Beliau adalah anak pertama dari dari 3 orang bersaudara, katiga saudara beliau bernama Haji Rasul, Faqih Burhanudin, dan Haji Ilyas. Haji sulaiman memperoleh pendidikan dasarnya dibeberapa tempat di Minangkabau. Awalnya beliau belajar membaca dan menghafal Al-Qura'an dengan ayahnya Haji Muhammad Saleh yang juga bekerja sebagai guru mengaji pada masa itu. Setelah tamat al-Quran beliau diserahkan ibu bapak beliau belajar agama dan berbahasa Arab ke berbagai macam pesantren dilingkungan daerah Sumatera Barat. Beliau terkenal gigih dalam menegakan faham syafi'iyah dan I'tiqa Ahlusunah waljamaah. Untuk itu beliau mau berkorban sebanyak-banyaknya. ${ }^{27}$

H.M.S. Sulaiman memiliki tiga orang istri, pertama Sa'adiah dengan istri pertama ini beliau memiliki 3 orang anak yaitu Maimunah, $H$. Muchtar dan Mansur st tumangguang. Istri kedua beliau bernama Sariman dengan istri

${ }^{26}$ Zulqayim, Bukitinggi Tempo Dulu (Padang: Andalas University Pres, 2006), 128. kedua ini beliau memiliki seorang anak bernama H. Prof. dr. Mahyudin. Ketiga Zuraidah berasal dari Padang Panjang anak dari Zainudiun Labay El Yunusiy. Dan dari istri ketiga ini beliau tidak memiliki keturunan.

Dalam bidang agama Haji Sulaiman termasuk ke dalam barisan kaum tua. Istilah kaum tua adalah golongan ulama yang tetap mengikuti salah satu mazhab yang empat dalam fiqih dalam konteks dunia melayu adalah mazhab syafi'i dalam akidah ialah ahlusunah waljama'ah yang berpedoman kepada dua orang imam yaitu Imam Abu Ahsan Al-Asyari dan Imam Abu Mansur Al-Maturidi.

Kedudukan H.M.S Sulaiman dalam barisan kaum tua dapat dilihat dari jabatan yang beliau pangku sebagai salah satu pendiri dari persatuan tarbiyah Islamiah (PERTI) pada tahun 1928 yang pada waktu itu beliau menjabat sebagai bendahara. H.M.S.Sulaiman juga menjadi salah satu pelopor berdirinya Bank Bumiputera, atau pada masa itu sering disebut dengan Abuan saudagar.

Pendirian bank bumiputera ini berawal dari cabang HIS (Himpunan Saudagar Indonesia) di Bukitinggi pada tanggal 27 desember 1930. pendirian ini di lakukan oleh HM.S Sulaiman bersama 9 rekan lainya yaitu, Anwar sutan saidi, H. Muhammad Yatim, Marzuki Datuak Mangulak Basa, H. Syamsudin, H. Mhd Thaer, Jamain Abd, Murad Tk. Mudo, H. Syarkawi Khalid, Rasyid St.Tumangguang, Malin Sulaiman, B.St Burhaman. Pada tahun 1931 abuan saudagar diubah ujud menjadi bank Nasional. $^{28}$

Kehadiran Bank Nasional telah memberi mamfaat bagi para pedagang di Bukittinggi. Selain itu kehadiran bank nasional sebagai bank bumi putera yang pertama di sumatera barat, juga telah melengkapi kota Bukittinggi sebagi kota perdagangan regional.

\footnotetext{
${ }^{27}$ Yahya, Riwayat Ulama Syafia'i, 34.

28 Zulqayim, Bukitinggi Tempo Dulu, 126.
} 
Sisi lain dari aktifitas H.M.S Sulaiman adalah mendirikan toko buku dan percetakan yang diberi nama firma Mathba'ah Islamiah yang tumbuh subur di kota Bukittinggi. percetakan ini berhasil mencetak Al-Quran dan karya-karya ulama-ulama pada masa itu. Dalam melakukan ini saya tidak bisa menemukan foto pribadi dari H.M.S Sulaiman, berdasarkan informasi yang saya dapatkan dari cucu beliau, beliau lebih suka sebagai pendorong kemajuan dari pada tampil lansuang. Tak jarang pada masa itu para ulama-ulama lainya datang berkunjung ke toko beliau selain membeli buku juga bertukar fikiran dengan beliau. H.M.S Sulaiman wafat pada 3 Ramadhan 1972 M,Semoga arwah beliau ditempatkan Allah pada tempat yang sebaik-baiknya.

\section{Permodalan dan Pekerja}

Pada awalnya penerbitan dan percetakan bermunculan untuk menyapaikan aspirasi dan kepentingan kelompok atau organisasi terntentu. Sehingga dimodali oleh kelompok dan organisasi tersebut. Hal ini berbeda dengan Mathba'ah Islamiah yang sumber pembiayaan penerbitan Mathba'ah Islamiah ini berasal dari uang milik pribadi H.M.S.Sulaiman dan juga hasil dari uang langganan pembaca yang tidak diketahui berapa jumlahnya karena H.M.S Sulaiman juga sering membagi-bagikan buku secara gratis kepada sekolah-sekolah agama.

Percetakan yang berdiri dalam tiga periode ini tidak hanya memepekerjakan masyarakat pribumi saja tetapi juga pekerja dari luar hal ini disebabkan karena pemesanan alat-alat keluar membutuhkan warga asing. Pada zaman belanda pembukaan di pegang lansung oleh pekerja dari Belanda dan pada saat pembuataan Al-Quran klisenya dibuat oleh pekerja dari Jepang yang tak lain pada waktu itu juga bekerja sebagai mata-mata Jepang. Pekerja yang tidak diketahui jumlahnya juga berasal dari warga pribumi

Setelah pemerintahan Belanda berakhir dan Jepang mulai berkuasa pekerja dari Jepang tersebut tak lagi bekerja dipenerbitan Mathba'ah Islamiah sehingga yang bekerja saat itu berasal dari masyarakat pribumi saja dan dibantu oleh anak-anak beliau. Masyarakat pribumi yang bekerja pada penerbitan tersebut berasal dari kota-kota Bukittinggi, karena jika mengambil pekerja dari Desa itu membutuhkan waktu untuk mengajarkan mereka cara menggunakan teknologi percetakan. Sedangkan jika warga yang berasal dari kota umumnya mereka sudah mulai mengerti dengan teknologi. Gaji yang mereka dapatkan pada masa itu sesuai dengan upah yang ditetapkan pada masa mereka bekerja.

\section{Penjualan Dan Promosi}

Buku-buku yang telah diterbitkan akan sampai kepada tangan pembaca dengan beberapa cara, biasanya mereka memesan langsung kepada pengarang atau penerbit. Untuk menginformasikan buku-buku terbitanya penerbit biasanya memasang iklan diberbagai surat kabar, majalah dan iklan dalam buku yang diterbitkan. Hal ini sangat efektif untuk menjangkau pembaca dari berbagai tempat dan kalangan, hal ini terlihat dari banyaknya surat kabar dan majalah yang mengiklankan buku-buku yang akan terbit, telah terbit atau hanya mengiklankan penerbit saja. surat kabar dan majalah menjadi media utama untuk penerbit mengiklankan bukunya.

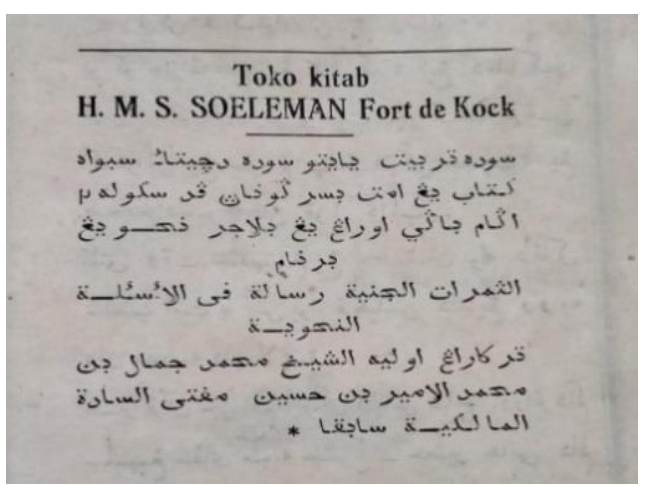

Gambar 1. Iklan buku-buku terbitan Mathba'ah Islamiah di surat kabar.

Meskipun cara seperti itu telah dilakukan sejak masa awal perkembangan penerbit buku. 
Namun pada mulai tahun 1921 iklan-iklan semakin menjamur dan lebih bervariasi. Kemudian terdapat juga ruang khusus dalam surat kabar dan majalah yang menginformasikan buku-buku yang diterima redaksi surat kabar dan majalah. Surat kabar dan majalah biasanya memberikan ruang khusus (rubrik) untuk buku-buku yang baru diterima. Seperti majalah Soearti yang memberikan ruang khusus untuk menginfornasikan buku terbitan Mathba'ah Islamiah.

"Dari boek H.M.S. SOELEMAN fort de kock, kita dikirimi doea boeah boekoe yang di terbitakanja, jaitoe; (1) Boekoe choelasah tarich Islami (bh. Arab); (2) Doeroesoel insja' (Bahasa Arab). Kedoea boeko karangan hoofdredacteur kita toen H.siradjoeddin Abbas dan boekoe itoe soedah ditetapkan boet peladjaran disemoea madrasah Tarbijatoel Islamiah (lihatlah leerplan kita) Jang berkepentingan boleh memesan kepada penerbit dan boekhandel soearti ${ }^{29}$

Penjelasan iklan di atas, menerangkan bahwa buku-buku yang diterbitkan didominasi oleh buku-buku yang digunakan oleh sekolahsekolah Thawalib.

Tidak hanya dalam majalah Soearti, Mathba'ah Islamiah juga mengiklankan bukubuku yang mereka terbitkan pada surat kabar lain, salah satunya yaitu surat kabar Warta Perniagaan berikut ini.

TOKO KITAB- Dan Drukkerij, ISLAMLAH H .M.S.SOELEMAN

Mendjoeal bermatjam kitab, bahasa 'Arab dan bahasa melajoe serta berbagai sa'ir jang mengandoeng pengadjaran bagi laki laki, dan perempoean jang bersangkoetan dengan agama Islam. Djoega kitab jang kami keloearkan pengarangnja adalah oelama jang terpilih dan mansyoer sedangkan harga kitab-kitab seoanja kami jual dengan harga pantas PRISCOURANT KITAB BOLEH KAMI KIRIM PERTJOEMA KEPADA

${ }^{29}$ Fadila, Penerbitan Minangkabau Masa Kolonial, 119.

${ }^{30}$ Yahya, Riwayat Ulama Syafia'i, 34 .
BARANG SIAPA JANG MEMINTA Kami menunggu dengan hormat. ${ }^{30}$

Dalam iklan tersebut harga buku yang dijual tidak disebutkan hal ini disebabkan karena harga buku yang sering berubah kadang naik dan kadang turun. Penyebarluasan buku yang diterbitkan tidak hanya dalam ruang lingkup Sumtra's Westkust, akan tetapi juga berbagai daerah Nusantara, oleh karena itu tidak heran jika ada beberapa iklan buku dalam surat kabar yang menjelasakan diterimanya buku dari berbagai penerbit di luar Fort De Kock. Salah satu ulama dari luar yang menerima banyak buku dari H.M.S. Sulaiman adalah syekh Abdullah Wali. Ulama besar Aceh.

\section{Buku-Buku Terbitan dan Hubungan dengan Kaum Ulama}

Kedekatan HM.S Sulaiman dengan ulamaulama Minangkabau memberikan peluang baginya untuk menerbitkan naskah-naskah kitab ulama Minangkabau yang banyak digunakan untuk pelajaran di Madrasah. Selain itu Mathba'ah Islamiah juga melengkapi toko bukunya dengan kitab-kiab terbitan Mesir.

Kitab yang dicetak dan diterbitkan oleh Mathba'ah Islamiah diantaranya adalah AlQu'ran Al-Karim dan Terjemahannya yang dicetak pada rabi'ul akhir 1352H/1933M. Berdasarkan kolofonnya, Al-Quran ini ditasihkan dengan pedoman kaidah rasm usmani oleh Mahkamah Syari'iah Bukittinggi yang saat itu diketahui oleh Syekh Sulaiman Ar-Rasuli dan Haji Abdul Malik. Secara umum Al-Quran cetakan Mathba'ah Islamiah mirip dengan Al-Quran afif Cirebon yang berjumlah 539 halaman dengan 15 baris setiap halamnya. Surat alfatiah pada al-qura ini berjumlah 7 ayat dengan membagi ayat terakhir menjadi dua. ${ }^{31}$

31 Abdul Hakim, "Al-Quran Cetak Indonesia Tinjauan Kronologis Pertengahan Abad Ke-19 Hingga Awal Abad Ke-20," Subuf 5 (2012): 231-54. 


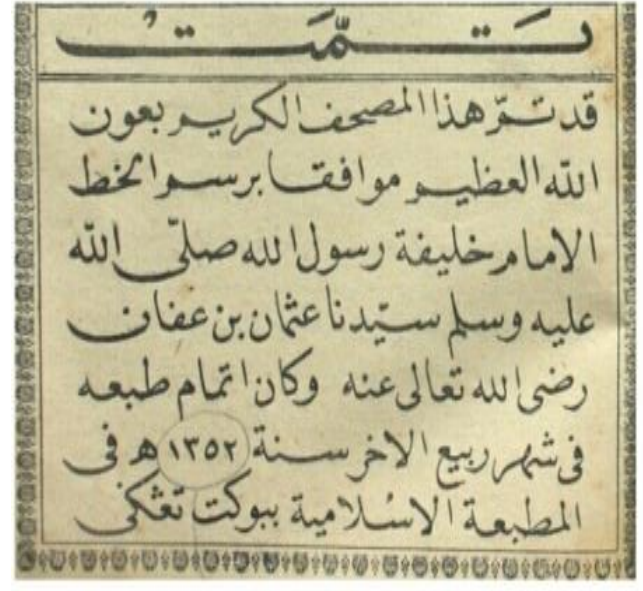

Gambar 2. Cuplikan Al-Quran terbitan Mathbaah Islamiyah dengan menggunakan kaidah rasm usmani.

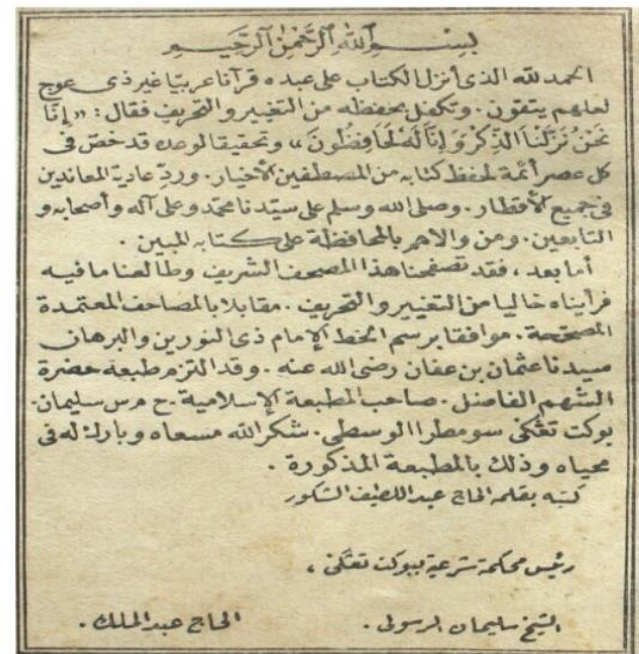

Gambar 3. Halaman pengantar untuk penerbitan Al-Quran oleh Mathbaah Islamiah.

Dalam bagian pengantar penerbitan $\mathrm{Al}-$ Quran tertulis selengkapnya:

"Segala puji bagi Allah SWT yang telah menurunkan Al-Qur'an dalam bahasa Arab yang tanpa kesalahan agar mereka bertakwa. Allah SWT juga menjaganya dari perubahan seperti firman-Nya" sesungguhnya kamilah yang menurunkan Az-Zikra dan sungguh kami-lah yang menjaganya . sebagai bukti atas janji-NYa, setiap masa selalu ada segolongan umat yang menghafalnya, salawat dan salam kepada Sayyidina Muhammad SAW, para sahabat, tabi'in dan siapa saja yang menjaga kitab-Nya. Amma ba'du, kami telah mentahshih mushaf ini, dan menelaah apa yang ada di dalamnya. Kami menmukan taqyir dan tahri. Sudah sesui dengan mushaf-mushaf yang mu'tamad dan benar. Sesui dengan rasm kaht imam Zurainin Sayyidina Usman Bin Affan r.a dan telah sah untuk dicetak oleh percetakan Mathba'ah Al-Islamiyah HMS Sulaiman, Bukittinggi, Sumatera Tengah. Syukur ke hadirat Allah SWT, semoga keberkahan selalu terlimpah kepada percetakan ini.

Ditulis oleh Haji Abdul Latif Syakur Ketua Mahkamah Syariah Bukittinggi Syeikh Sulaiman Ar-Rasuli-Haji Abdul Malik."32

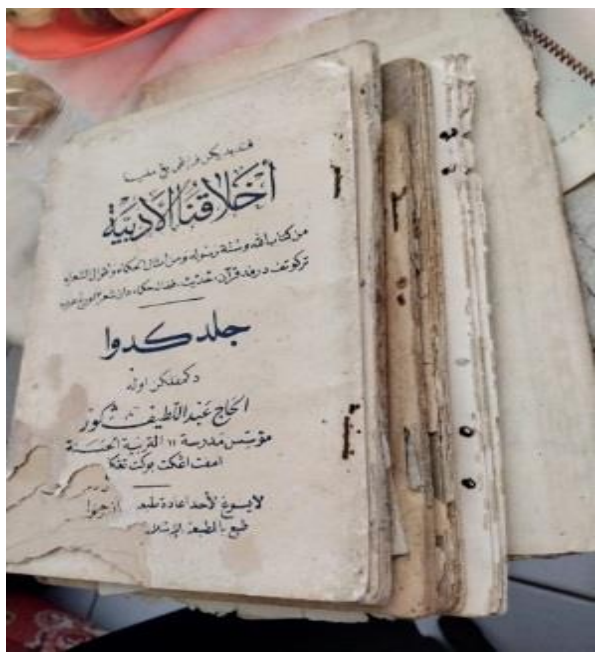

Gambar 4. Beberapa buku terbitan Mathbaah Islamiah.

Karya-karya ulama Minangkabau yang diterbitkan oleh HMS. Sulaiman di antaranya adalah karangan Syekh Sulaiman Arrasuli yang berjudul Kitab Aljawabir Kalamiyah fi Bayanaqa'id Al-Imaniyah (1927), Dawa'ul Qulub fi Qhishas Yusuf wa Ya'qub(1927), Al-Aqwalu Al-Mardiyah (1933), Risalah Al-Qaulul Bayanfi Taftiril Qur'an (1928), dan Al-Aqwalul Mardiyah fi Al'aqaid AdDiniyah yang diterbitkan berulang kali di Mathba'ah Islamiah untuk pelajaran di madrasah Tarbiyah hingga saat ini.
32 Hakim, Abdul Hakim, “Al-Quran Cetak Indonesia Tinjauan Kronologis Pertengahan Abad Ke19 Hingga Awal Abad Ke-20,” 231-54. 
Tidak hanya karangan Syekh Sulaiaman arRasuli, Mathba'ah Islamiah juga menerbitkan buku karangan ulama lainya, Di antaranya adalah buku karangan Syekh Abdul Latif Syakur pada tahun 1927 dengan judul Kitab Tarbiyah AlIslamiyah fi Durus Al-Fiqbiyyah dan Kitab AtTabiyat wa Ta'lim Qismut Tabuid. Syekh Muhammad Dalil Bayang, Majmu' Musta'mal Yang Menyatakan Rukun Syarat Yang Terkandung dalam Agama Islam; Yahya Al-Khalidi Magek, Jalan Kebahagian; Jalaludin Al-Kusai Sungai Landai, Rislah Syarat Sembahyangb dan Rukun Iman Serta Akidah Iman; Labia Sidi Rajo, Nazam Nabi Bercukur yang masing-masing tidak diketahui kapan tahun diterbitkanya. Buku karangan Ismail bin Abdullah al Minangkabawi, Mawabib Rabbil Falaq Syarh Qashidah Binti AlMaliq (1928); karangan Angku Mudo bin Syekh Abdul Ghani Guguak Tinggi dengan judul, Kitab Empat Risalab (1) Pemulaian I'tiqat Kepada Allah, (2) Anwarul Iman (3) Mau'izhah, (4) Nurul Hidayah yang diterbitkan pada tahun 1931.

Selain itu Mathba'ah Islamiah juga menerbitkan buku karangan ulama kaum muda yaitu karangan Abdul Karim Amrullah yang berjudul Al-Bash'ir; Dalil-Dalil Yang Kuat, Pemandanga Yang Hebat, Penolak Segala Kesamaran dan Styubhat yang diterbitkan pada tahun $1357 \mathrm{H}$ dan beberapa buku yang tidak ketahui pengarangnya diantaranya adalah, asal pangkat penghulu dan pedirinya (1927), pertalian adat dan syarak yang terpakai di Alam Minangkabau lareh nan duo luhak nan tigo (1927), dan Risalah Al-Qaul Al Bayan fi Tafsir Al-Qura'an (1929).

Tidak hanya buku karangan ulama Minangkabau Mathba'ah Islamiah juga melengkapai penerbitan dengan buku-buku Agama yang digunakan untuk pendidikan di sekolah-sekolah agama terutama sekolah tarbiyah Islamiah yang didirikan oleh ulama kaum tua. Meskipun buku-buku yang diterbitkan oleh Mathba'ah Islamiah sangat sulit ditemukan, akan tetapi beberapa ulama dan penulis masih menggunakan buku-buku terbitan Islamiah sebagai referensi penulisan karya-karya mereka.

\section{Kesimpulan}

Mathba'ah Islamiah adalah satu toko buku dan percetakan yang berdiri di kota Bukittinggi yang menerbitkan karya-karya ulama Minangkabu dan kitab-kitab yang agama yang dipelajari di madrasah-madrasah. Tidak hanya menerbitkan buku-buku karangan ulama Minangkabau tetapi juga mencetak al-quran terjemaah yang sesui dengan rasm usmani yang tak kalah dari cetakan luar. Mathba'ah Islamiah juga melengkapi toko bukunya dengan mendatangkan kitab-kitab terbitan dari Mesir dan mendistribusikanya ke sekolah-sekolah agama yang membutuhkan.

Keberhasilan Mathba'ah Islamiah ini di sokong oleh pendirinya yaitu H.M.S Sulaiman seorang ulama yang berasal dari kaum tua yang dikenal dermawan. Ketokohan Haji Sulaiman sangat terkenal di kalangan ulama, terutama Persatuan Tarbiyah Islamiah.

Mathba'ah Islamiah adalah salah satu dari sekian penerbitan yang mampu bertahan dalam tiga zaman, yaitu zaman Belanda, zaman Jepang, dan setelah kemerdekaan. Walaupun penerbit ini kemudian hilang ditelan zaman, akan tetapi buku-buku yang diterbitkannya masih banyak dipakai dan dibaca terutama di kalangan pesantren dan marasah sebagai bahan ajar, dan juga digunakan para ulama sebagai bahan untuk menulis, hal ini misalnya ditemui di dalam beberapa buku dan jurnal yang masih menggunakan referensi buku-buku terbitan Mathba'ah Islamiah, terutama oleh Ulama Persatuan Tarbiyah Islamiah.

\section{Daftar Kepustakaan}

Abdurrahaman, Dudung. Metodologi Penelitian Sejarah Islam. Yogyakarta: Ombak, 2012.

Arsa, Dedi. "Pembentukan Masyarakat Literal di Sumatra Barat: Perkembangan Awal Perpustakaan dan Toko Buku," Khazanah 9, no. 1 (2019): 31-40. 
- Celana Pendek dan Cerita Pendek. Yogyakarta: Basabasi, 2008.

Fadila, Zikri. Penerbitan Minangkabau Masa Kolonial. Yogyakarta: Gre Publising, 2018.

Fadli, Muhammad Rijal. Sistem Ketatanegaraan Pada Masa Pendudukan Jepang. Jakarta: PT Prima. 2019.

Hakim, Abdul. "Al-Quran Cetak Indonesia Tinjauan Kronologis Pertengahan Abad Ke-19 Hingga Awal Abad Ke-20." Subuf 5 (2012): 231-54.

Koto, Alaidin. Pemikiran Politik Persatuan Tarbiyah Islamiah 1945-1970. Riau: UIN Suska Press, 1996.

Naldi, Hendra. Booming Surat Kabar di Sumatra's Westkust. Yogyakarta: Ombak, 2008.

Putra, Apria. "Drukkerij Al-Islamiah Fort de Kock: Penerbit Turats Ulama Minangkabau di Masa Pemerintah Belanda," Tarbiyah Islamiah 2, no.1 (2014):12.

https://tarbiyahislamiyah.id/drukkerij-alislamiyah-fort-de-kock-penerbit-turatsulama-minangkabau-di-masapemerintahan-belanda/.

. "Ulama dan Karya Tulis: Diskursus Keislaman di Minangkabau Awal Abad 20." Fuaduna: Jurnal Kajian Keagamaan dan Kemasyarakatan 1, no. 2 (2017): 134-47.

Shamad, Irhas, Danil M Chaniago. Islam dan Praktis Kultural Masyarakat Minangkabau. Jakarta: PT Tintamas Indonesia, 2007.
Sulasman. Metodologi Penelitian Sejarah. Bandung: Pustaka Setia, 2014

Sunarti, Sastri. Kelisanan dan Keberaksaraan dalam Surat Kabar Terbitan Awal Minangkabu18591940. Jakarta: Gramedia, 2013.

"Suara-Suara Islam dalam Surat Kabar dan Majalah Terbitan Awal Abad 20 di Minangkabau." Turas: Jurnal XXI, no. 2 (2015).

Yahya, Yunus. Riwayat Ulama Syafia'i. Magek: Persatuan Murid-Murid Tarbiyah Islamiah, 1976.

Zulqayim. Bukitinggi Tempo Dulu. Padang: Andalas University Pres, 2006.

Sumber-sumber Tertulis Primer:

"Redactie dan Administratie", Maanblad Soearti 1937.

Daftar Buku-buku Terbitan Mathba'ah Islamiah, 1927-1937.

Daftar Kitab-kitab Toko Kitab Firma H.M.S. Sulaiman dan Fort de Kock S.W.K. 1937.

Syekh Haji Yunus Yahya Magek, 1976, Riwayat Ulama Syafia'i. Magek; Persatuan MuridMurid Tarbiyah Islamiah.

Warta Perniagaan, 15 September 1927.

Wawancara

H. Haviz dt Manindiah (Cucu Kandung H.M.S Sulaiman), Wawancara, 31 Mei 2020.

Zamzami Yuus (Murid Syekh Sulaiaman Arrasuli), Wawancara, 18 Januari 2020. 